Liability: The Complicated Task of Licensing

\title{
CONF- $961113--13$
}

Law Enforcement Technologies

\author{
Larry W. Hops \& Trudy K. Overlin, M.P.A \\ Idaho National Engineering Laboratory \\ Lockheed Martin Idaho Technologies Company \\ P. O. Box 1625, MS 3855 \\ Idaho Falls, Idaho 83415-3855 \\ HWL@INEL.GOV \& OKT@INEL.GOV
}

\begin{abstract}
This paper discusses a situation where a company (licensor) requires a liability policy as a condition of a license agreement, when licensing law enforcement technologies. The purpose of this discussion is to evaluate the reasons behind the need for extensive liability policies to protect licensors when marketing their law enforcement technologies to private industry. Finding a solution to the problem, therefore reducing the potential for high liability insurance costs, would be desirable. Since the risks associated with most technologies are virtually unknown, and because such technologies are used in very unpredictable legal environments, alternative ways of guaranteeing research and development enterprises that they will be covered against product liability are needed. Without such protection, licensors may require licensees to indemnify them beyond the usual guarantees provided in a licensing agreement, which may make the license too costly for smaller businesses. When the share of the market is limited to larger corporations, competition suffers and ultimately the cost to law enforcement agencies increases.
\end{abstract}

Keywords: license, licensor, licensee, indemnification, risk, litigation

\section{INTRODUCTION}

Currently, researchers and developers are faced with the prospect of requiring a liability policy on all law enforcement technologies they license into the private sector. The insurance policy is required to fill the void above that covered by the usual indemnification clause contained in the license agreement. Typically when a company is sued on a product liability matter, the developer shares the liability with the law enforcement agency, manufacturer, marketing and sales companies. It is considered risky to develop high profile technologies for law enforcement use because those most affected by these are also those most likely to seek legal action. This action can be against a law enforcement agency and anyone connected with the development or use of the product. A law suit may arise although the injury or damage might be minimal. Even if the claim is unsubstantiated by a court of law, it often creates considerable expense for all parties. As a result, many companies seek to settle out of court, while not admitting any wrong doing, they are simply attempting to cut their losses. This often provides a question as to the safety or validity of a particular product because it has not been successfully defended, causing other potential users to delay purchasing or using the 


\section{DISCLAIMER}

This report was prepared as an account of work sponsored by an agency of the United States Government. Neither the United States Government nor any agency thereof, nor any of their employees, make any warranty, express or implied, or assumes any legal liability or responsibility for the accuracy, completeness, or usefulness of any information, apparatus, product, or process disclosed, or represents that its use would not infringe privately owned rights. Reference herein to any specific commercial product, process, or service by trade name, trademark, manufacturer, or otherwise does not necessarily constitute or imply its endorsement, recommendation, or favoring by the United States Government or any agency thereof. The views and opinions of authors expressed herein do not necessarily state or reflect those of the United States Government or any agency thereof. 
product.

Individuals involved in criminal activity are often in perilous states of mind, where they will do anything to avoid apprehension, even attempting an escape while being transported to jail. Suspects in a patrol vehicle, for instance, may seek to kick out windows, doors and/or protective shields in an attempt to set themselves free. Individuals are often cut, bruised, battered or severely injured if they are successful in freeing themselves from the vehicle and fall to the pavement while the vehicle is still moving. Although the vehicle, and the equipment in the vehicle, have performed as they were designed, the probability of a law suit still exists. A case in point occurred in Kootenai County, Idaho, where a suspect was in transport to the county jail. This suspect was correctly placed in hand cuffs, properly secured in a seat belt, and placed in the patrol vehicle. Despite proper procedures, the suspect managed to free himself from the restraint and kicked the door open. The suspect then proceeded to jump from the vehicle while it was still in motion, sustaining numerous injuries. The officers took the suspect to a hospital where he was treated for his injuries. After he was released, the suspect sued the Kootenai County Sheriff's Department for the failure of the officers to protect him during transport. The suspect was successful in winning a monetary award, and between the award and the legal fees, the State of Idaho and Kootenai County incurred a sizeable bill. This is a case where officers followed procedures, used equipment properly, and yet the individual's own lack of common sense cost the agency and the tax payers a great deal of money. The suspect here was the winner, while the original criminal act went npunished. This type of condition adds to the unknown risks associated with licensing and manufacturing law enforcement technologies.

\section{CURRENT SITUATION}

The consequences of our litigious society make the climate of licensing technologies very risky and complicated for any licensee. Beyond design concerns, are issues of proper field testing, variations in the materials used during manufacture, proper field training and application, appropriate record keeping and actual maintenance of a technology. No one entity can control all of these factors in the life of a product. Each party is equally vulnerable in being named in a suit, simply because they were part of the life cycle a particular technology. This is the case regardless if their portion of the product life cycle is not in question.

Organizations funded with federal dollars need to be unbiased when licensing technologies. Smaller businesses often cannot afford the required insurance coverage imposed by the licensor. This condition creates an unfair advantage for larger organizations by making it more difficult to do business with the smaller firms. This condition tends to shrink the market size which can add to product cost, or cause considerable problems in getting needed technologies into the field. This condition may limit the effectiveness of the research and development organization because it reduces the number of companies available for licensing. Many less sophisticated, (less-tech) devices are better suited to the "mom and pop" companies which may be eliminated from competition due to the high cost of liability insurance. Law enforcement needs these less-tech type technologies in the near term to support current needs. Technologies that researchers originally designed to be less expensive, improvements on 
existing field technologies which were to be on the market in a relatively short time period, are not meeting that goal ${ }^{2}$.

It is safe to assume this condition may discourage the research and development funding organizations by dampening their researchers' desires to propose valuable technologies. This situation exists because law enforcement technologies run the risk of not being licensed upon completion. This situation also burdens would be manufacturers who rely on government funded research to assist them in producing technologies that they could not afford to otherwise manufacture. They may not have the available research and development funds for design and prototype development, but would have the ability to bring these technologies to the law enforcement market. It affects competition between research organizations, those which have additional insurance requirements above the indemnification of the license, and those that do not. Since most of the emerging technologies in law enforcement have no field history, the risks associated with their application cause licensors to choose an arbitrary insurance requirement based on the propensity of legal action. Just like the new vehicle that is unknown for its performance in protecting its occupants during an accident, insurance companies (or in this case licensors) have to protect themselves against the unknowns, especially litigation expenses which can be in the millions of dollars.

At this time there is no systematic way to determine appropriate levels of coverage so policy limits are frequently established at higher than necessary levels to protect the development organization. Time is of the essence in bringing a product to the market. Determining what level of insurance to require is in many cases a time consuming endeavor which may delay the licensing process. This condition adds to the burden placed upon the research organization who simply cannot get their technologies to market in a timely manner. Competition in high technology is too fast paced to have these types of unnecessary delays. Also, a determination as to whether these levels of coverage are necessary is simply not discernable without in-depth study. Products that may expose the general public to the slightest risk are the ones that take the greatest "hit" when it comes to establishing an insurance policy limit. Trying to secure against all unknown risks that cannot be anticipated is an additional factor that drives up insurance coverage requirements.

Research laboratories are concerned with protecting the legal rights and assets of their contracting organizations as well as protecting the engineers and scientists who develop the technologies. Typically these contracting organizations have "deeper pockets", therefore they are prime targets for larger law suits involving hundreds of thousands of dollars in damage awards. The awards are not necessarily generated by design flaws, but because of improper use, witless human action, improper use of materials in manufacture, ineffective quality control, or other issues not related to design.

\section{RESPONSIBILITY AND ACCOUNTABILITY}

Laboratories and researchers are not seeking to be totally removed from responsibility for their products, but are endeavoring to be protected in cases where injuries occur in instances beyond which their original product design. The types of materials used, product installation and 
maintenance, training in use and record keeping cannot be controlled by the researcher, nor should they be. When an item is inappropriately used the responsibility for injury can possibly fall at the feet of the researchers, developers and manufacturers to remedy all conditions. In other words, any one seeking to develop technological solutions to a perplexing law enforcement problem may be discouraged because our society occasionally believes that individuals are not to held accountable for their actions, regardless of how ridiculous those actions may be.

The litigious public, in many product liability cases, is seeking compensation for their own witless actions. Many times they are not responsible or accountable for making less than intelligent decisions regarding the use or misuse of a product. Suspects, while being transported in patrol vehicles, who choose to jump out while the vehicle is still moving, may not have considered their actions. Had they been rational they certainly would have known that there was a high potential for injury. The fact that the criminal act is circumvented by litigation to protect someone who willfully caused their own injury burdens not just law enforcement and would be technology designers, but the public in general.

\section{DISPARITIES IN INSURANCE REOUIREMENTS}

Technologies licensed into the private sector from federal research and development facilities are licensed according to the environment they will be used. It makes little difference if a technology is potentially fatal if used incorrectly, if it is utilized in a controlled environment where the risks of a fatality are perceived to be lower, and the general public is not exposed. The insurance required in such cases may be minimal, beyond the indemnification provided in the license agreement. The likelihood of legal action is a driving factor regarding the requirement for additional insurance premiums. Product liability cases take on strange twists which predicate additional risks to research and developing laboratories. These twists prompt risk assessment personnel to apply conservative risk values to a technology, which results in more expensive insurance policies for the licensee. Since there is no reasonable way to control these risks, or determine their residual effects, analysts must compensate for any assessment errors. The environment in which these technologies are ultimately deployed is at least questionable.

It would be desirable for government funded research and development projects to be more marketable. In order for this situation to occur, the current levels of required insurance coverage need to be lowered or systematically determined based on in-depth study. For this to happen a method of federal indemnification needs to occur, or another method to reduce the risk factors needs to be developed. Either task is not a simple one, and would require a great deal of effort on the part of the granting organizations who fund law enforcement technology research. Although it is beyond most granting organization's purview in that they are funding needed research, they have to be able to assist the researchers in solving this issue. Litigation is hindering these organizations which would prefer to be investing dollars into research to solve problems, rather than defending their position on behalf of a technology that met the original design challenges. When these conditions are resolved, the market for law enforcement technology will become more competitive. 


\section{PREVIOUSLY LICENSED TECHNOLOGIES AND PRODUCT LIABILITY}

The trend toward requiring insurance coverage, beyond the original indemnification clause, appears to be a corporate response to unknowns and with the associated risks. The policy requirement appears to be arbitrarily based upon the propensity for a law suit, rather than the actual physical harm that may occur if a device is misused or fails to perform properly. It is also associated with the type of environment in which it will be used. A potentially fatal technology, for example, if used in a laboratory environment with security and safety provisions, may not require an additional policy. The theory behind this relates to the type of professional using the device, and the fact that all persons associated with the use are in the laboratory confines. This provides the perception that all individuals associated with the laboratory will use the device properly, taking all necessary precautions. It also assumes that any affected individual will not choose to litigate if an accident occurs. The risk to the general public is therefore non-existent.

This assumption may prove to be critically false however, the known environment and safety factors do provide the licensor with a sense of security about the use of a product. Within the confines of law enforcement multiple unknowns exist. Although an officer may be trained to use a device, and clearly acts professionally, the intended victim or public may not be so inclined. The environment is not always limited to the security of a laboratory, and often others may be in the vicinity when a tool is used. The presence of the public, the erratic nature of the fleeing suspect, and the pressure exerted on the officer, are concerns for developers and hence it is reflected in their license agreements.

This is not a universal condition, some corporations are taking greater risks. They are confident in their designs, therefore they are not placing a high probability on litigation. Why the disparity between laboratories, corporations and private vendors? A multiple of reasons may exist, but these do not make for clear interpretations as to why some require insurance beyond the license, and some do not. Risk assessments cannot be an exact measure of risk potential due to many unknowns, therefore insurance coverage is often established at higher levels. If a government entity or insurance company could define acceptable liability levels, or law suits were limited to certain dollar figures, perhaps this would be an easy task to resolve. Since risks involve unknowns, and liability limits have not been imposed, the complexity of these issues are enormous. This condition lends itself to a disparity in coverage requirements which may result in unfair competition.

\section{GOVERNMENT INDEMNIFICATION}

It would be desirable for the federal government to indemnify the licensor or to establish limits on monetary awards granted to litigants in product liability cases regarding law enforcement technologies. These factors would encourage more companies to invest in further developing prototypes and manufacturing technologies for law enforcement. Without such support, the introduction of new law enforcement related technologies may be reduced. 
The researchers indicate that technologies in this field are warranted and valuable, and they desire to find solutions to solving law enforcement problems and making the streets safer for both officers and the public. However contractors who generally operate federal research facilities, and even private vendors, have to protect their business interests and assets against losses. A law suit that involves a poor behavior choice, versus actual product liability, makes this situation even more difficult. When a resolution to the litigation issue is found, and the costs associated with law suits decreases, researchers and developers will feel free to introduce new technologies to satisfy the needs of officers in every agency.

\section{CONCLUSIONS}

Unfortunately few answers exist in solving the liability question in regard to law enforcement technologies. The potential for legal action will continue to be a factor in the assessment of policy levels required by licensors for their licensees. The added costs associated with these high premiums also increase the costs associated with technologies, and therefore drive up the cost to law enforcement customers. Ultimately the public pays the price for such costs in terms of technologies that do not ever reach the market where they are sorely needed and would be useful. An increase in fees and taxes to pay for such technologies may also occur. What is the middle ground on this issue? Is there an easy solution, or a solution at all? The answer lies in a complexity of issues which need to be resolved if technologies are going to make it into the field where they are needed. We need to solve these issues in order to encourage the development of needed technologies. If litigation is going to continue as a driving force behind any technology application, the future for law enforcement technologies is more grim and disappointing. We need to start holding individuals accountable for wilful actions that lead to negative consequences. We need to put solving crime above monetary rewards, and we need to resolve the litigation issues which surround technologies developed in this environment. If we cannot solve the issues of product liability, and continue to ignore human accountability in terms of wilful actions, we will all suffer the consequences.

\section{ACKNOWLEDGMENT}

This work is supported by the U.S. Department of Energy, under DOE Idaho Operations Office Contract DE-AC07-94ID13223. This paper however, does not necessarily express the opinions of Lockheed Martin Idaho Technologies Company, the Idaho National Engineering Laboratory, the U.S. Department of Energy or Lockheed Martin Corporation.

\section{REFERENCES}

1. John Doe vs. Kootenai County Sheriffs Department, and Deputy Gary Cuff, Kootenai County District Court, August, 1988. (Case settled without full trial)

2. Marts, D.J., and Overlin, T. K., "The Advantages of Less-Tech, Less-Than-Lethal Technologies", Public Safety/Law Enforcement Technology, Proceedings, SPIE, The International Society for Optical Engineering, Law Enforcement Symposium, April, 1995, Pages 60-68. 